\title{
PERFIL SOCIAL DA POPULAÇÃO NEGRA NO BRASIL: Implicações para a profissão enfermagem ${ }^{1}$
}

\author{
SOCIAL PROFILE OF BLACK POPULATION IN BRAZIL: IMPLICATIONS FOR NURSING \\ PROFESSION.
}

\section{Ana Lúcia Jezuino ${ }^{2}$}

\begin{abstract}
RESUMO: A discussão sobre as condições de desigualdades em que vive a população negra no Brasil vem sendo mascarada pela conjuntura econômica vigente, que aparentemente coloca sem restrições brancos, negros e mestiços em condições de destituição absoluta. País considerado sem racismo, intitulado pela Folha de São Paulo/ Datafolha de "Racista Cordial", vem instituindo formas de convivência entre as raças, cuja discriminação está expressa na falta de oportunidades e acesso ao consumo de serviços. Desta forma, a inserção do negro na sociedade brasileira, após a abolição da escravatura, vem a ser nosso objeto de estudo. Este levantamento bibliográfico discute os indicadores sociais, tendo como objetivo descrever as estratégias de luta desta população na conquista de um espaço social. Foram evidenciadas as dificuldades encontradas por este grupo populacional no que tange à sua inserção no mercado como fator determinante de sua ascensão social; é neste grupo que incluímos como cidadãos os negros e negras, que compõem a força de trabalho em enfermagem.
\end{abstract}

UNITERMOS: Racismo - Desigualdade social - Força de trabalho.

\begin{abstract}
The discussion about the inequality conditions in which black population lives in Brazil, has been disguised by today's economical conjuncture which apparently sets with no restrictions the white, black and mestizos in absolute destitution conditions. Considered unracist, entitled by 'Folha de Sao Paulo / Datafolha' as Kind Racist, Brazil has being instituting way of living among races whose discrimination is expressed by the lack of opportunity and access to consumption services. This way, the insertion of the black in Brazilian society after slavery abolition is our study object. This bibliographical discusses social indicatars aiming at describing this population strategies in conquering a social space. This study shows up the difficulties faced by this populational group regarding to its insertions to the work market as determinant factor to its social rising. We have included black male and female as citizens which compose the labor force in Nursing.
\end{abstract}

KEYWORDS: Racism - Social inequality - Labor force.

\footnotetext{
${ }^{1}$ Trabalho apresentado no $9^{\circ}$ SENPE - Vitória - Espírito Santo, julho de 1997.

2 Professora do Departamento de Enfermagem Fundamental e Administração da Faculdade de Enfermagem Luiza de Marillac/ SBSC.
} 


\section{INTRODUÇÃO}

No Brasil, a discussão do referido tema assume uma superficialidade capaz de convencer a sociedade da inexistência de atitudes racistas em relação a essa parcela da população. Aqui a cordialidade do racismo adquire formas de fraternidade em épocas de catástrofe, de parcerias no período do carnaval e de exclusão quando o assunto passa para a esfera do acesso a serviços e competitividade, o que é diferente de países eminentemente racistas como o Estados Unidos da América, onde foram travados verdadeiros combates étnicos pela conquista da cidadania da população negra.

Essa visão distorcida do racismo no Brasil impediu-me por muito tempo de pensar e tratar o assunto num trabalho. Meus olhos estavam vendados, e não conseguia distinguir no sistema social vigente a existência de discriminação entre negros e brancos por ser a sociedade brasileira tão miscigenada.

Foi então, como aluna especial do curso de doutorado da EEAN/UFRJ, cursando a disciplina "A questão social no Brasil no Contexto Latino-americano", que, em cumprimento das atribuições acadêmicas, assumi o desafio de apresentar no seminário os indicadores sociais da população negra, mesmo que essa tarefa me trouxesse recordações mal resolvidas durante minha vida profissional, as quais nunca consegui metabolizar através da reflexão do significado de ser negra numa sociedade onde o racismo é tão velado.

Diante das incertezas, do medo e da dificuldade em lidar com o referido assunto, no primeiro momento, ao selecionar as referências bibliográficas, percebi que a discussão sobre as condições de desigualdades em que vive a população negra no Brasil vem sendo mascarada pela conjuntura econômica vigente, que aparentemente coloca sem restrições brancos, negros e mestiços em condições de destituição absoluta.

Pensar em destituição significa pensar em pobreza, e se discutirmos a pobreza, segundo a visão de Abranches (1985), compreendê-la-emos como destituição, marginalidade e desproteção. Para o referido autor, destituição significa estar à margem dos meios de sobrevivência física; marginalização representa a impossibilidade do indivíduo usufruir dos benefícios do progresso, principalmente do acesso às oportunidades de emprego e renda; e finalmente caracteriza desproteção como falta de amparo público adequado e inoperância dos direitos básicos de cidadania, que incluem garantia à subsistência e ao bemestar. ${ }^{1}$

No entanto, no Brasil, a ausência de conflitos étnicos aparentes, vem instituindo formas de convivência entre as raças de extrema cordialidade, cuja discriminação se expressa nos limites dos direitos básicos de cidadania, levando-nos à hipótese de que a discriminação racial em nosso país se sustenta no tripé da destituição, marginalidade e desproteção.

Com o aprofundamento da pobreza, a penetração de práticas discriminatórias é algo tão comum, costumando seguir os hiatos entre repressão e democracia em que vive a população negra na sociedade brasileira, após a 
abolição da escravatura. Assim sendo, o objetivo deste estudo é o de descrever as estratégias de luta mais importantes desta população na conquista de um espaço social.

Para tal, optamos pela pesquisa bibliográfica por entender que ela oferece meios para explorar áreas onde os problemas não se cristalizaram suficientemente, como é o caso do tema em questão. Foram selecionados, entre as diversas referências, os livros "O povo brasileiro" e "Racismo Cordial" como base de nossas reflexões.

$\mathrm{Na}$ busca por dados que dessem conta da discussão sobre as condições de exclusão/pobreza deste grupo social, selecionamos alguns dados estatísticos do IBGE/PNAD sobre educação do chefe da familia renda/número de dependentes por família e distribuição geográfica.

No sentido de dar uma organização lógica ao trabalho, a primeira parte consta de breve historia das formas de organização da população negra desde a época da escravatura até os dias atuais. $\mathrm{Na}$ segunda, discutiremos os indicadores sociais que determinam estatisticamente a destituição e a existência do racismo. Finalizando discutiremos a proposta da discriminação positiva, estratégia de luta deste grupo populacional na conquista de um espaço social, diante desse mercado sem fronteiras, dito competitivo, ora se desenhando no mundo global.

\section{CONQUISTANDO ESPAÇOS SOCIAIS}

Historicamente a raça negra chegou no Brasil, como escravos, procedente da África. Vendidos como mercadorias, trabalhavam nas lavouras e no setor de extração de minério, em precárias condições de sobrevivência, pois eram substituidos com facilidade no mercado negreiro.

A primeira estratégia de liberdade é a fuga. O conhecimento das matas lhes garantiam sobrevivência longe das amarras de seus senhores. As sucessivas fugas resultaram em organizações de comunidades coletivas, chamadas de quilombos, instituindo o primeiro movimento de resistência.

Livres continuavam sob a mira dos poderosos que a todo momento faziam investidas contra os negros aquilombados. Por outro lado, alguns conseguiam a alforria, mas tal conquista geralmente se tornava um pesadelo. Segundo Ribeiro, (1996) "contavam apenas com sua força de trabalho, num mundo em que a terra e tudo o mais continuava apropriado. Nessas condições, o negro forro, que alcançava de algum modo certo vigor, poderia, só por isso, sendo mais apreciado como trabalhador, fixar-se em alguma fazenda, ali podendo viver e sobreviver. O débil, o enfermo, o precocemente envelhecido no trabalho, era simplesmente enxotados como coisas imprestáveis".

A falta de liberdade fez com que a raça negra se adequasse. Aprendem a falar o idioma português através dos berros do capataz, e o fazem com desenvoltura, conseguindo emprestar ao português a singularidade dos dialetos africanos. Na realidade, ao aprender o novo idioma ocorre a uniformização da 
comunicação entre eles, considerando a diversidade dos dialetos das diferentes tribos africanas.

Para Ribeiro, ao aprenderem um novo idioma, os negros conseguem comunicar-se com outros companheiros de diferentes povos, evoluem neste momento de meros animais de carga para seres humanizados, capazes de manterem um nivel de organização que protegeu por séculos os negros fujões aquilombados ${ }^{7}$.

Em 1871, foi aprovada a Lei do Ventre Livre que concedia liberdade para os filhos de escravos nascidos a partir daquela data. Esse ato jurídico trouxe um problema social maior do que a escravidão, pois os donos das escravas colocaram as crianças nas ruas, abandonando-as literalmente.

Diante do primeiro abandono coletivo de crianças, no mesmo ano foram fundados nas vilas e cidades asilos para acolher as crianças, atiradas fora pelos fazendeiros ${ }^{7}$. Pode-se dizer que foi uma das primeiras medidas sociais instituídas pelo governo português em favor da população negra.

Nesta época, mesmo com a proibição de tráfico de negros imposta com a Lei Euzébio de Queirós, as classes dominantes viam essa população de escravos, forro, bem como o mulato, como mera força energética comparada com um objeto que, ao ser desgastado, é substituido. Desta forma, mesmo depois de 13 de maio de 1988 com a assinatura da Lei Áurea, que extinguiu a "escravidão" no Brasil, o negro, ao envelhecer, por não ser produtivo, era colocado de lado ou expulso das fazendas caindo em condições de miserabilidade.

Para alguns fazendeiros, essa lei favoreceu a substituição dos negros, trabalhadores manuais, por imigrantes estrangeiros que traziam em sua bagagem maior qualificação técnica.

O entendimento de que os indivíduos de raça negra são seres apropriados para serviços pesados passa de pai para filho e assume na atualidade uma característica cultural. Segundo Ribeiro (1996), com a evolução dos tempos, descendentes da burguesia da época do Brasil escravagista continuavam a ver o negro livre, o mulato e o pobre como o resto da humanidade, tendo em vista a preguiça, ignorância e criminalidade inatas.

Ribeiro (1996) continua sua análise, dizendo que "a nação brasileira comandada por gente dessa mentalidade nunca fez nada pela raça negra que a construíra". Negou-lhe a posse de qualquer pedaço de terra para viver e cultivar; de escolas em que pudesse educar seus filhos e de qualquer ordem de assistência $^{7}$.

Diante dessa fictícia liberdade os negros, no primeiro momento para fugirem do "apartheid" social, são aliciados para o trabalho sob as condições ditadas pelo latifúndio. Depois traçam estratégias para terem acesso à terra, dentre as quais destacamos a defesa da nação em guerras, os serviços escusos prestados às famílias poderosas e a prostituição por parte das mulheres. 
Uma das mais valiosas armas da mulher negra sem dúvida foi a utilização do seu próprio corpo, a caminho da liberdade. No entanto, esse movimento corporal que a transformava geralmente em um mero objeto era utilizado como espaço de dominação sexual, que avançava e repensava as formas de obtenção da "Liberdade" no sentido pleno da palavra. É o caso de mulheres como Xica da Silva, Maria da Fé, as amas de leite e as negras de ganho.

O "marketing" do corpo da mulher negra, veiculado atualmente durante o carnaval, reforça essa sexualidade. São nádegas protuberantes, bem contornadas e molejo nos gestos e gingas que acabam por expressarem o reconhecimento de sua negritude.

É no movimento do corpo que essas mulheres passam a ser autoras de sua própria história, através do auto-reconhecimento de suas limitações na sociedade. Constróem seu próprio discurso sobre si, sobre o seu corpo, e estabelecem formas de luta que garante espaços nas passarelas do samba, da moda e nos demais setores da economia.

No ramo da imprensa, o lançamento de folhetos denunciando as barbáries dos senhores contra seus escravos formava a imprensa alternativa que tratava de assuntos referentes ao povo negro. Como exemplo, o Jornal Mestiço representa instrumento de grande valia no movimento abolicionista. ${ }^{4}$

Durante as décadas de 60 e 70, jornais, como Ébano Jornal (SP), Niger (SP), Afro Chamber (SP), Sinhá (RJ), Tição (RS), foram, editados. Como veículos de comunicação da comunidade afro-brasileira, resistem à ditadura e ao eurocentrismo cultural. ${ }^{4}$

Entretanto, nenhuma dessas publicações conseguem sobreviver ao massacre cultural imposto pela classe dominante, constituída majoritariamente de indivíduos brancos, que descaracterizaram a imprensa negra através do discurso de que as posições de desvantagens entre as raças era fruto da imaginação dos militantes do movimento negro.

Somente na década de 90, a exemplo dos negros americanos, surge no Brasil, a revista RAÇA, que apresenta para a opinião pública um negro belo, sem medo, competitivo e de sucesso. Descobre uma parcela da população ávida a consumir produtos específicos da raça, que pesam na balança comercial do pais.

Outra estratégia de luta dos negros são os movimentos, entendidos como desnecessários pela maioria dos negros, imprescindiveis para os intelectuais e desprezados pelos meios de comunicação. É através das organizações não governamentais que entendemos ser possivel zelar e disseminar a cultura negra. Cuti (1991) entende que a proposta de reescrever a história deve ser uma proposta prioritária, a fim de "resguardar o presente, para que não se torne um passado completamente esquecido debaixo do tapete dos que têm o poder". 2

Por isso, destacamos o movimento da Frente Negra Brasileira instituído, em 4 de novembro de 1931, com a publicação na íntegra de seu estatuto em Diário Oficial. 
Estimulados com a expectativa de participação social criada na década de 20, com as revoltas em busca de melhorias sociais, o que contribui para aumentar a conscientização da população de uma maneira geral. Segundo Isaltino, citado por Cuti (1991), "a Frente Negra Brasileira, surgiu sob a égide da revolução de 30".

Organização verticalizada, de caráter autoritário, a Frente Negra Brasileira custou a se transformar num partido político. Somente em 10 de novembro de 1937 esse movimento foi reconhecido como partido político e no dia 2 de dezembro do mesmo ano Getúlio Vargas decretou o fechamento de todos os partidos. Neste momento a Frente passa a ser União Negra Brasileira, apenas com os objetivos sociais e culturais.

Movimentos recentes aglutinam negros em verdadeiros guetos que, pressionados pela classe dominante, acabam transformados em massa de manobra ou associações sócio-culturais, sem convicção de que o espaço negro nessa arena é bem menor do que o espaço branco, estabelecendo, de início, posições de desvantagens visíveis.

Mas, mesmo assim, essas organizações tentam superar as contradições utilizando estratégias de intervenção, centradas nas diferenças de oportunidades estabelecidas historicamente entre as raças, em nosso pais.

\section{OS LIMITES DA CORDIALIDADE DO RACISMO}

Abordar a questão da discriminação racial no Brasil é uma tarefa árdua, tendo em vista as representações sociais estabelecidas nos diversos segmentos da sociedade desde o Brasil Colônia.

$\mathrm{Na}$ verdade, a população sabe que existe, nega sentir, mas demonstra preconceito contra os individuos de cor preta e parda. Como diria Silva, "os dados oficiais confirmam que a simples vivência do cotidiano já nos aponta com clareza: no Brasil, a destituição social não é daltônica." Sendo assim, existem representações sociais que determinam a diferença entre as raças. ${ }^{11} \mathrm{~A}$ começar pela enfermagem, cuja composição da força de trabalho é constituida em sua maioria de individuos negros e pardos. Se ousássemos perguntar numa determinada região sobre a quantidade de enfermeiras negras que ocupam cargo de direção, na área de ensino e serviço, levariamos um bom tempo para selecioná-las.

Na verdade, essa indagação não é fácil de responder, se observarmos que, apesar das oportunidades serem as mesmas na estrutura sócio-econômica do país sua determinação está estreitamente relacionada com a coloração da pele do indivíduo.

Não pretendo estimular a revolta entre as raças, mas discutir dados estatísticos que nos fazem refletir sobre a triade destituição, marginalidade e desproteção, cujos resultados recaem com mais intensidade sobre as pessoas de cor negra, mais susceptíveis e próximas da linha da pobreza. 
O primeiro dado a ser discutido é a localização da residência, segundo as características da cor, nas diversas regiões do Brasil. Os brancos em sua grande maioria se localizam em áreas industrializadas, como São Paulo e Região Sul, enquanto que os negros, na região sudeste, são mais numerosos no Estado do Rio de Janeiro, mantendo equilíbrio nos demais Estados desta região em relação à população branca. Entretanto a maior concentração de negros e pardos se dá na região nordeste.

Segundo pesquisa da DATAFOLHA, a maior manifestação racista entre os entrevistados foi encontrada na região nordeste, que apresenta um alto índice de miscigenação.

Esses dados apontam apenas para distribuição geográfica não demarcando as condições da moradia. No entanto, pode-se inferir que a população negra residente nas áreas metropolitanas e urbanas não metropolitanas vivem majoritarimente em favelas, casas de cômodos e muitos já se tornaram população de rua.

No que diz respeito à renda familiar, relacioná-la-emos com o número de dependentes por família, pois, quanto maior o número de dependentes, mais recursos financeiros são necessários na manutenção da qualidade de vida (Tabela 1).

Conforme relatório recente sobre desenvolvimento humano, "o rendimento médio dos homens pretos e pardos correspondiam em 1990, respectivamente, a $63 \%$ e $68 \%$ do rendimento dos homens brancos. A posição relativa da mulher preta e parda em relação à mulher branca é semelhante: seu rendimento correspondia a $68 \%$ do rendimento da mulher branca" ( Gráfico 4).

Desta forma, em relação aos salários, a população negra e parda recebe de $1 / 4$ a 1 salário-mínimo, enquanto a população branca detém os mais altos salários declarados na Pesquisa Nacional por Amostra de Domicílios (PNAD) -1988. Por outro lado, são também essas famílias que acabam, por falta ou dificuldade em assimilar as informações, tendo um grupo familiar constituído de 5,7 e mais dependentes.

Rodrigues (1996) analisa que $50 \%$ dos negros têm uma renda individual mensal equivalente a, no máximo dois salários-mínimos. Esse percentual cai para $45 \%$ entre pardos e para $40 \%$ entre os brancos. No topo mais alto da pirâmide salarial, outro desastre para os negros. Enquanto $16 \%$ dos brancos entrevistados recebem por mês o equivalente a dez ou mais salários-mínimos, apenas $6 \%$ dos negros se encaixam nessa categoria." Estes dados constatam que o poder de compra do negro na escala social é menor do que o do branco. Além disso, a ascensão salarial no Brasil está relacionada à escolaridade e qualificação do trabalhador.

Esse dado coloca a população negra na linha da pobreza, que, segundo o estudo de Rocha e Tolosa, (1989) deve ser mensurada pelo nível de $1 / 4$ do maior salário-mínimo vigente no país, em 1980, e conseqüentemente efetuar correção para os anos subseqüentes de acordo com o índice geral de preços 
(IPG). Usando a metodologia de Hicks e Vettor (1983), Rocha e Tolosa partem do princípio que a pobreza absoluta deve ser mensurada o valor de uma cesta básica de consumo obtida por meio de pesquisa direta e avaliada segundo vetores de preços locais.

Constataremos que na atual conjuntura o grupo que recebe de $1 / 4$ a 1 saláriomínimo não consegue comprar alimentos para sua subsistência, quanto mais arcar com os custos de habitação, saúde, educação e lazer, sendo privado de serviços essenciais, e automaticamente destituidos de uma parcela significativa dos direitos de cidadania.

Um dos critérios lançados na mídia, estabelecido para alcançar os padrões modernos de desenvolvimento, vem sendo a qualificação da força de trabalho, o que está relacionado com o nivel de escolaridade dos indivíduos e a proporção de investimentos voltados para essa área pelos governos.

Contraditoriamente, ao mesmo tempo que se ampliam as taxas de escolarização, ocorre crescimento absoluto acentuado do índice de analfabetismo. Dentre os países da América Latina, o Brasil tem a segunda maior taxa $(18,7 \%)$ de analfabetismo, só perdendo para a Bolivia, segundo IBGE (1993).

Esse fato nos fez analisar os dados relacionados à educação do chefe da família. Em sua maioria, observamos que os pretos e pardos, estão na linha de semi-instruídos ou com menos de um ano de instrução, sendo ínfimo o grupo que consegue chegar aos bancos da universidade. $O$ mesmo não acontece com a população branca que mantém a taxa de escolaridade entre 3 a 9 anos de instrução (Gráfico1).

Em pesquisa de opinião, a DATAFOLHA constatou que apenas $4 \%$ dos entrevistados negros conseguiram passar em algum vestibular e entrar para um curso de nivel superior. Entre os brancos o percentual sobe para $13 \%$. É notado, também na tabela que $71 \%$ dos entrevistados negros e $57 \%$ dos entrevistados brancos estudaram até o $1^{\circ} \mathrm{Grau}$, comprovando a total ineficiência dos serviços prestados pelo Estado na área de educação (Venturri e Paulino, 1995).

O quadro acima desenhado traduz a disparidade de oportunidades oferecida para negros e brancos; quando desprovido de escolaridade, o chefe da família acaba deixando para seus filhos a mesma herança. A luta constante pela sobrevivência coloca precocemente seus dependentes no mercado de trabalho, impedindo crianças e adolescentes de permanecerem nos bancos escolares durante o período pré-escolar e escolar, o que contribui para destituição e marginalização, em particular da população negra.

Tal panorama vem a modificar-se, mesmo que timidamente, quando um negro consegue se destacar - quebra-se o encanto e posteriormente seus dependentes conseguem superar as barreiras do racismo social e passam a dar maior importância aos bancos escolares como estratégia de conquista do espaço social. 
Por outro lado, para resolver este problema, algumas administrações estaduais e municipais vêm implementando programas de renda mínima, que investem na manutenção das crianças e adolescentes na escola.

\section{CONSIDERAÇÕES FINAIS}

No que pese as afirmações de que a discriminação racial no Brasil não existe, substituindo-a por critério de beleza, que exclui negros, pobres, deficientes e velhos, ficarei com a análise de que a existência do racismo neste país segue a lógica perversa da delimitação dos espaços destinados a negros e brancos.

A convivência pacífica nos impede de vislumbrar que, mesmo quando os dados estatísticos demonstram que o negro, em fase de recessão econômica, vem mantendo-se empregado, este dado não contempla a essência da realidade. $\mathrm{Na}$ verdade, os postos de emprego ocupados pela raça negra geralmente estão relacionados a serviços braçais qualificados de atividades simples e repetitivas, desprovidas de criatividade e de desenvolvimento do intelecto. É o caso na área de enfermagem dos trabalhadores de formação elementar, atendentes ou similares.

A exclusão se dá no acesso à escola, ao mercado de trabalho e ao sistema de informação. Nesta linha, crianças, adolescentes e jovens negros, herdeiros absolutos da miséria imputada pelo Estado Brasileiro a seus pais ao longo desses anos, desde o Brasil colônia até os dias de hoje, encontram-se sem perspectivas. Compelidos ao consumo, essa população acaba por ceder às pressões de contraventores, iniciam uma carreira que a principio, não fossem os riscos, Ihes oferece oportunidades de ascensão "profissional". Neste mercado, começam transportando drogas, passam ao cargo de soldados e podem chegar a gerentes do crime.

Um ponto comum entre jovens e adultos negros é o consumo da maior parte de suas energias em prol da sobrevivência por um triz, pois, quando não morrem de fome e desilusão, são vítimas da violência. A opção oferecida pelo submundo do crime não é perfeita diante dos riscos, mas representa atualmente a solução para a população negra que vive na linha da pobreza, próxima da indigência, até que sobrevenha a morte.

Diante da discriminação passada e presente contra os negros e pardos, a idéia da discriminação positiva garante a igualdade racial através da reserva de parte das vagas nas universidades e dos empregos nas empresas, para a população negra. Quem sabe, com a implementação dessa proposta, se restabeleça a democracia racial principalmente na área de educação e no mercado de trabalho. 


\section{ANEXO}

TABELA 1 - INCIDÉNCIA ABSOLUTA E RELATIVA DA CARÊNCIA (RENDA FAMILIAR ATÉ $1 / 4$ S. M. PER CAPITA) PELA COR DO RESPONDENTE E NÚMERO DE PESSOAS DEPENDENTES NA FAMILIA (1988) (EM MILHARES DE PESSOAS)

\begin{tabular}{|c|c|c|c|c|c|c|c|c|c|c|}
\hline \multirow{3}{*}{$\begin{array}{c}\text { Ne DE DEPENDENTES } \\
\text { NA FAMILIA }\end{array}$} & \multicolumn{10}{|c|}{ COR } \\
\hline & \multicolumn{2}{|c|}{ Branca } & \multicolumn{2}{|c|}{ Preta } & \multicolumn{2}{|c|}{ Parda } & \multicolumn{2}{|c|}{ Amarela } & \multicolumn{2}{|c|}{ TOTAL } \\
\hline & $\mathrm{Fi}$ & $F \%$ & $\mathrm{Fi}$ & $\mathrm{F} \%$ & $\mathrm{Fi}$ & $F \%$ & $\mathrm{Fi}$ & $F \%$ & $\mathrm{Fi}$ & F\% \\
\hline 0 & 199 & 4,2 & 44 & 9,4 & 235 & 10,2 & - & - & 480 & 6,30 \\
\hline 1 & 832 & 6,2 & 138 & 11,1 & 1.031 & 15,6 & 3 & 1,7 & 2.004 & 9,30 \\
\hline 2 & 1.699 & 8,5 & 254 & 17,6 & 2.117 & 20,9 & 6 & 2,9 & 4.076 & 12,80 \\
\hline 3 & 2.400 & 13,1 & 339 & 27,4 & 3.358 & 30,9 & 3 & 1,8 & 6.161 & 20,00 \\
\hline 4 & 2.270 & 21,3 & 340 & 38,6 & 3.634 & 40,9 & 17 & 21,9 & 6.315 & 30,65 \\
\hline 5 & 1.603 & 31,5 & 348 & 42,8 & 3.353 & 54,3 & 9 & 24,0 & 5.313 & 43,80 \\
\hline 6 & 1.076 & 46,9 & 314 & 65,1 & 2.209 & 60,7 & 6 & 49,1 & 3.605 & 56,10 \\
\hline $7 a 10$ & 1.115 & 65,8 & 298 & 75,1 & 3.063 & 71,0 & - & $=$ & 4.482 & 69,90 \\
\hline 11 ou mais & 35 & 88,0 & 25 & 95,2 & 102 & 84,2 & - & - & 162 & 86,60 \\
\hline
\end{tabular}

Fonte: IBGE, PNAD-1988. Tabulações especiais

GRÁFICO 1 - INCIDÊNCIA RELATIVA DA CARENCIA (RENDA FAMILIAR ATÉ 1/4 S. M. PER CAPITA) PELA COR DO RESPONDENTE E EDUCAÇĀO DO CHEFE DA FAMÍLIA (1988)

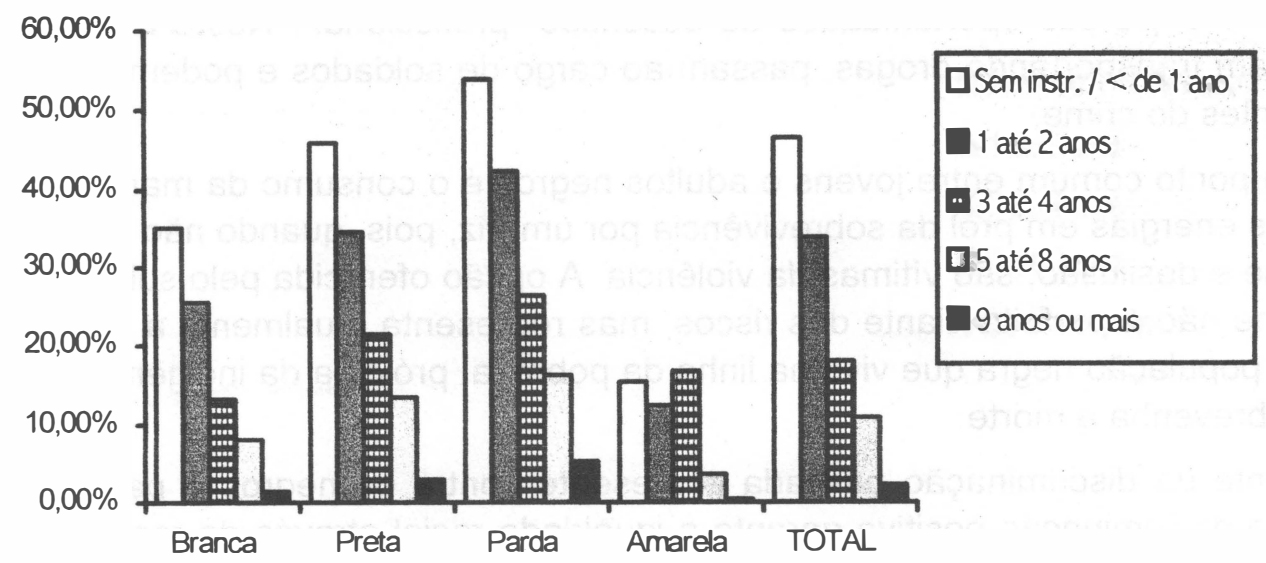

Fonte: IBGE, PNAD-1988. Tabulações especiais.

Legenda: Educação do chefe da família. 
GRÁFICO 4 - RENDA FAMILIAR PER CAPITA POR COR DO RESPONDENTEBRASIL (1988)

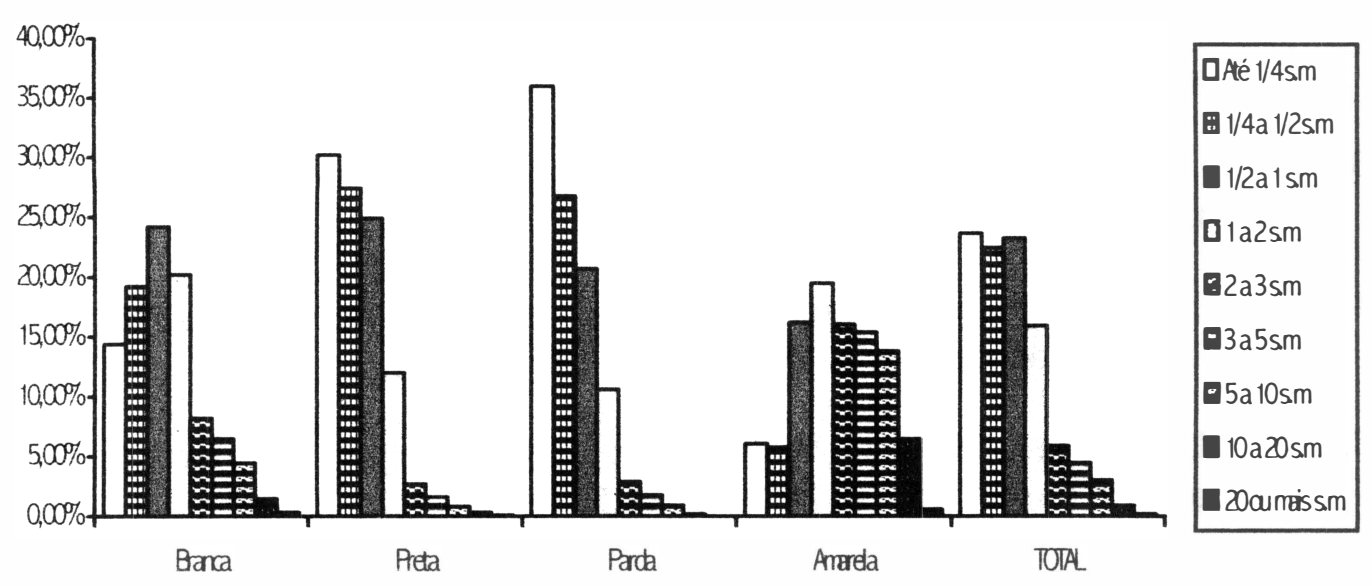

Fonte: IBGE, PNAD - 1988. Tabulações especiais. (Obs.: s.m. = salário-mínimo.) 


\section{BIBLIOGRAFIA}

1. ABRANCHES, S. H. Crescimento e Pobreza no país da pobreza. 2 ed., Rio de Janeiro: Zahar, 1985.

2. CUTI, L . Frente à Frente negra brasileira". R. Proposta, Rio de Janeiro: Fase. n. 51, p. 28-24, nov. 1991.

3. IBGE. Jane Souto de Oliveira (Org), Traços da Desigualdade Social no Brasil. Rio de Janeiro, 1993.

4. IORUBÁ, J. Imprensa Negra e Liberdade de Imprensa. R. Proposta. Rio de Janeiro: Fase, n. 51, p. 26-27, nov. 1991.

5. ISABEL, M. Sexualidade e Identidade da Mulher Negra. R. Proposta, Rio de Janeiro: Fase, n. 51, p. 22-24, nov. 1991.

6. LAKATOS, M,E. e MARCONI, M, A. Técnicas de Pesquisa. 3 ed., São Paulo: Atlas, 1996.

7. RIBEIRO, D. O Povo Brasileiro - A formação e o sentido do Brasil. 2 ed., São Paulo: Companhia das Artes, 1996.

8. RODRIGUES, F. Racismo Cordial. Folha de São Paulo / Datafolha, São Paulo: Átila, 1995.

9. SINGER, P. Radiografia da democracia racial brasileira, in: Racismo Cordial. Folha de São Paulo/Datafolha, São Paulo: Átila, 1995.

10. TAVARES, S, L. BRASIL - Pobreza nos anos 80 e Início dos anos 90. Rio de Janeiro, 1997. Mimeografado

11. VENTURRI, G. e PAULINO, M, F. Pesquisando preconceito racial, In: Racismo Cordial. Folha de São Paulo/Datafolha, São Paulo: Átila, 1995.

12. ROCHA, S. e TOLOSA, H. Pobreza Metropolitana e Políticas Sociais. In: Perspectivas da Economia Brasileira, IPEA/INPES, 1989. 